\title{
DETERMINANTS OF CLOUD COMPUTING ADOPTION BY ROMANIAN SMES IN THE DIGITAL ECONOMY
}

\author{
Violeta Mihaela DINCÄ (D)1, Alina Mihaela DIMA (D2², Zoltán ROZSA (D)3 \\ 1,2UNESCO Department for Business Administration, \\ Faculty of Business Administration in Foreign Languages, \\ Bucharest University of Economic Studies, Bucharest, Romania \\ ${ }^{3}$ Department of Management and Human Resources Development, \\ Faculty of Social and Economic Relations, Alexander Dubcek University in Trencin, Slovakia
}

Received 15 December 2018; accepted 28 March 2019

\begin{abstract}
The purpose of this paper is to explore the process of Cloud Computing adoption within Romanian Small and Medium sized Enterprises in the digital age. Most of the scientific papers related to this topic examine the general outlook of cloud computing implementation in Romania and focus on the use of the afore-mentioned technologies by large scale companies. In order to identify the factors that have an influence over the choice of Romanian SMEs to adopt cloud computing technology, a conceptual model has been set forth. The model's dependent variable is the choice of the company's management to implement cloud computing technologies. Five different independent types of variable structures which have an effect on the adoption of cloud computing within SMEs were identified. The five categories of variables are competition \& government, ICT providers \& firm departments, employee, manager and technological factors. Each of these categories of determinants encompasses at their turn two or more constructs.

An online survey tested the model based on the responses of managers and directors from 198 Romanian SMEs from the cities of Bucharest and Cluj. The validity of the model was performed by completing factor analysis and reliability tests of the data; a logistic regression analysis was deployed to test the research hypotheses. The results emphasized that the managers' know-how on cloud computing and the perceived costs of implementing the technology represent the main components influencing the spreading of cloud computing among Romanian SMEs. This study makes a valuable contribution to the academic environment but to businesses as well. The model can be used to examine the implementation of different innovative applications. Companies which offer cloud computing services could take advantage of the outcomes of this study to expand the degree of cloud service introduction among SMEs.
\end{abstract}

Keywords: cloud computing, Romanian SMEs, theoretical model, technology adoption, quantitative study.

JEL Classification: L86, L22, B23.

${ }^{\star}$ Corresponding author. E-mail: alina.dima@fabiz.ase.ro

This is an Open Access article distributed under the terms of the Creative Commons Attribution License (http://creativecommons. org/licenses/by/4.0/), which permits unrestricted use, distribution, and reproduction in any medium, provided the original author and source are credited. 


\section{Introduction}

In the present digital age, organizations are faced with highly global, interconnected, and dynamic environments (Fonseca \& Domingues, 2017). The emergence of the phenomenon known as cloud computing represents a fundamental change in the way that are developed, delivered, updated, maintained and paid IT services in modern organizations. For the companies from an emerging economy, a profound consequence of this digital expanding consuming (Nistoreanu, Dinca, \& Schiopu, 2017) is the necessity to invest permanently amounts of money in equipment used to process and stock data. Cloud computing services become true incubators for the new applications, meant to respond to the high demand of getting information fast and easy (Greavu-Șerban, 2015).

SMEs are regarded as a main source of innovation, growth and competitiveness (Hadad, 2017), being an important aspect of the economy locally and internationally (Kallier, 2017) and therefore the SMEs' capacity for innovation and flexibility makes them pivotal for Romania's progress in the European economy based on the Digital Single Market Strategy advanced by the European Union (Foerster-Pastor \& Golowko, 2018). The Romanian economy is supported in proportion of $99.66 \%$ by SMEs which ensure two out of three jobs within the private sector and provide more than half of the total added value created by businesses in Romania (European Commission, 2016).

For this reason, planning new approaches or advancing new procedures that can support SMEs to boost their efficiency and productivity is not only of use to SMEs but also to the economy as a whole (Dobeš, Kot, Kramoliš, \& Sopková, 2017; Cepel, Stasiukynas, Kotaskova, \& Dvorsky, 2018). In the recent international scientific literature, many researchers (Alshamaila, Papagiannidis, \& Li, 2013; Gupta, Seetharaman, \& Raj, 2013; Sultan, 2011; Balcerzak \& Pietrzak, 2017) claim that the digital technologies and ICT are used to improve the decisionmaking process for businesses. However, for small businesses, their size and their structure frequently put them in the position of dealing with challenges and even though adopting new technologies gives a chance to SMEs to increase their competitive advantage, it regularly implicates high financial resources.

The context of the research is given by an evolving computing paradigm - cloud computing - which now intends to offer fully virtualized computing services to users. Of all the descriptions of cloud computing, it is worth to mention the one provided by the Oxford Dictionary which states that cloud computing represents "the practice of using a network of remote servers hosted on the internet to store, manage, and process data, instead of using a local server or a personal computer" (Stevenson, 2015). Tvrdikova states that cloud computing is important because it helps maintaining the continuity of information system of enterprises with low financial impact, thereby increasing its stability (Tvrdikova, 2013). The purpose of the paper is to research the cloud computing phenomenon in the context of SMEs because they can gain different advantages from using it, ranging from easier business administration and reducing investment, operation and maintenance costs, to better responding to the business requirements and gaining global access (Zell \& Swanson, 2017).

The structure of the paper includes: the literature review, analyzing similar studies dealing with cloud computing implementation by SMEs in different economies; the methodology, de- 
scribing the conceptual model, along with the hypotheses, the participant companies and the interviewing process analysis; the results part which performs different statistical procedures in order to test the validity of the proposed construct model and its advanced hypotheses which address different factors that could influence the adoption of cloud computing within SMEs. The conclusions section reveals aspects such as a comparison between the results and expectations along with the limitation of the study.

\section{Literature review}

In the last few years the notion of cloud computing has come to light as a dynamic and optimistic answer to the dares linked to declining IT financial resources and widening IT necessities. Buyya, Yeo, Venugopal, Broberg, and Brandic (2009) described cloud computing as "a type of parallel and distributed system consisting of a collection of interconnected and virtualized computers that are dynamically provisioned and present as one or more unified computing resources based on service-level agreements established through negotiation between service provider and customer", whilst Plummer defined cloud computing "a style of computing where massively scalable IT-related capabilities are provided as a service using Internet technologies to multiple external customers" (Plummer, Bittman, Austin, Cearley, \& Smith, 2008).

Following are the five main characteristics of cloud computing (Mell \& Grance, 2011; Sasikala, 2011) that offer the greatest advantages: on-demand self-service, broad-network access, resource pooling, rapid elasticity and measured service.

For SMEs cloud computing promises to deliver tangible business benefits, often at much lower cost as they only pay for the resources needed, offering them good return on investment of their limited resources. In turn they can focus on what truly delivers value to their customers and results in a competitive advantage (Alshamaila, Papagiannidis, \& Li, 2013).

Management of costs is one of the most serious problems of SMEs and it is not pragmatic for SMEs to overspend on their Information Technologies (IT), which apart of the high investment, usually involve an important uncertainty of underachievement (Henderson \& Weiler, 2010; Jain, 2011; Smith, Cearley, \& Plummer, 2009).

Cloud computing, an innovative computing model, makes it possible for SMEs to gain access to complex technologies without investing major expenses (Buchaelcevova \& Gala, 2012). Several diverse theories and models have been suggested to inquire how new technologies are adopted.

Between these models, the diffusion of innovation theory (DOI - Figure 1) is one of the most generally applied theories that analyze, interpret and estimate the adoption of technologies. The Diffusion of Innovation is a theory advanced by Rogers which was introduced first in the sociology field (Rogers, 2003). Most of these models interpret and foretell the adoption choice, grounded on components that are associated with the technology itself (attributes of the technology, or consumers' insight about the technology). Nevertheless, factors associated with technology are not the only ones that determine the adoption of technologies. Other influencers are important as well (of environmental and organizational nature) for the preference of a certain innovation. These factors, particularly those related to environmental issues, 
are not being considered within the DOI theory. However, Rogers proposes that four main elements influence the spread of a new idea: the innovation itself, communication channels, time, and a social system (Choi, Kim, \& Lee, 2010). This process relies heavily on human capital and this element is also one which importance is being underlined within this study by the choice of the model's variables.

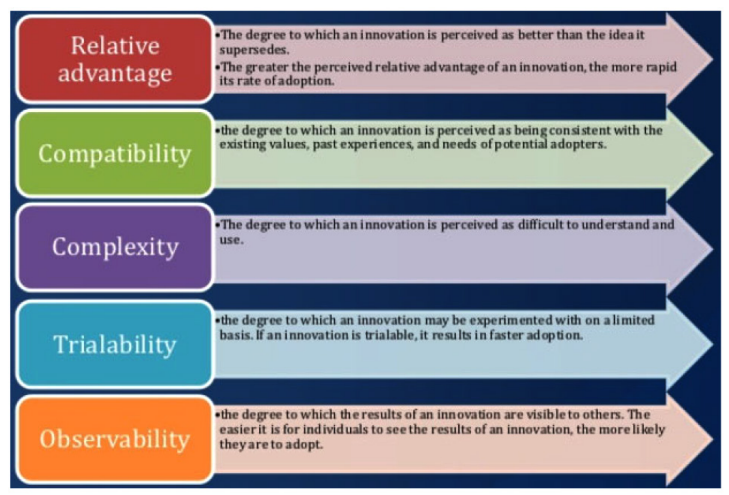

Figure 1. The DOI theory framework (source: Rogers, 2003)

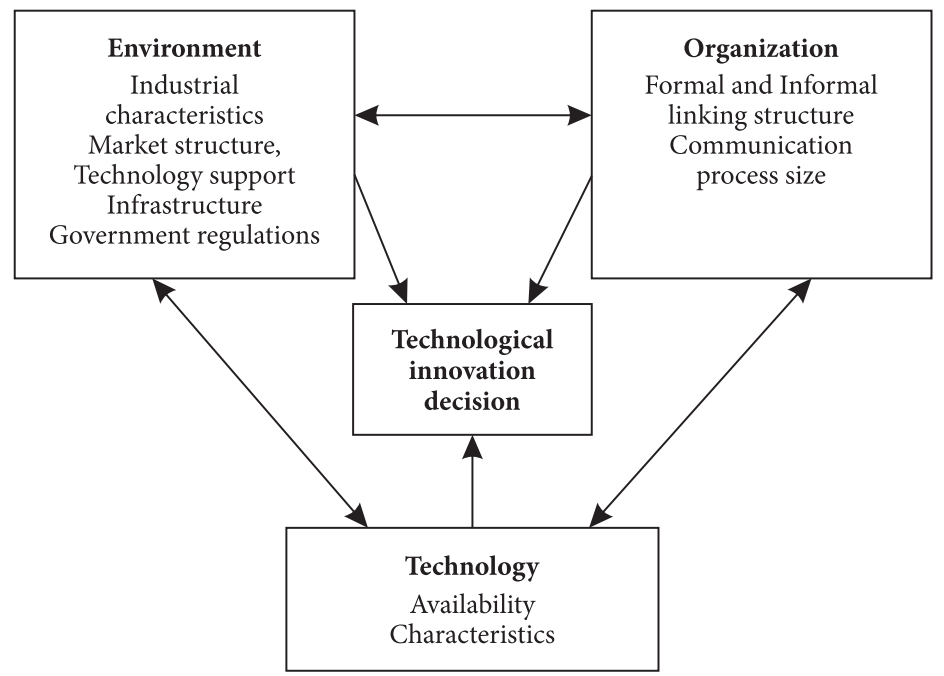

Figure 2. The technology-organization-environment framework (source: Tornatzky \& Fleischer, 1990)

Technology-Organization-Environment (TOE) as presented in Figure 2 is another theoretical pattern that covers this shortcoming. This outline makes use not only of technological features of the dissemination process, but also of non-technological perspectives with environmental and organizational elements.

Because these frameworks have weaknesses, with none of them being totally perfect, in this scientific paper, a research model is proposed which is founded on DOI and TOE components, but created in a different way, in order to explain more precisely the adoption of the 
technology (distinctively of cloud computing) for the Romanian business environment. The objective of this article is to synchronize and adapt Rogers's DOI and the TOE framework to the cloud computing adoption process for Romanian SMEs.

In spite of its importance, the number of studies focusing on the cloud computing adoption methods within SMEs is not very high. Most importantly would be to mention two important studies carried out after 2010. The first study was a qualitative one, developed by Yazn Alshamaila and Savvas Papagiannidis from the Newcastle University Business School together with Feng Li from the Cass Business School in London with the purpose of analyzing the cloud computing adoption process within 15 SMEs from north east England. The model used as a backbone for the determinants of the adoption process was the Technological, Organizational and Environmental (TOE) framework without any adaption or modification. The main factors that were identified as playing a significant role in SME adoption of cloud services were: relative advantage, uncertainty, geo-restriction, compatibility, trialability, size, top management support, prior experience, innovativeness, industry, market scope, supplier efforts and external computing support (Alshamaila, Papagiannidis, \& Li, 2013).

The second SMEs' study which was thoroughly examined within the literature review portion of the research belongs to Gupta and Seetharaman from the SP Jain School of Global Management in Singapore together with Raj from the Multimedia University in Malaysia. This research reveals the perception of 211 SMEs from India, Singapore, Malaysia and USA towards different factors influencing cloud computing adoption within the respective companies, factors which were grouped into five constructs in order to build a model with the independent variable being the decision to adopt cloud computing technologies (a similar approach to the one used in the present paper). The results concluded that among the five constructs (cost savings, ease of use, reliability, security \& privacy and sharing \& collaboration) "ease of use \& convenience" together with "security \& privacy" were the top priorities for the companies consulted to adopt cloud computing, while "cost savings" and "reliability" were the least important features influencing the organizations to implement cloud computing technologies.

\section{Aim, research design, and methodology}

The purpose of this paper is to explore the process of cloud computing adoption within Romanian Small and Medium sized Enterprises. More particularly, it tackles the influential factors as well as the opportunities and challenges in the area of cloud-based technologies adoption by Small and Medium Enterprises in Romania.

\subsection{Research design}

With the scope to identify the factors that have an influence over the choice of Romanian SMEs to adopt cloud computing technology a conceptual model has been set forth, which is based on two well-known theories of this scientific area - the DOI and the TOE frameworks. The model includes variables which were considered the most suitable for the SMEs' frame of reference, having the DOI and TOE as background but with a few changes in order to ensure originality to the changes and to be more adapted for the Romanian economic reality. The model's dependent variable is the choice of the company's management to imple- 
ment cloud computing technologies, therefore the Romanian SMEs which participated at this study were required to mention whether they adopted cloud computing or not by the time of the survey. Five different independent types of structures (of variables) which have an effect on the adoption of cloud computing within SMEs were identified and it is the influence of these five structures of variables on cloud computing adoption that is researched in this study. The five categories of variables are competition \& government, ICT providers \& firm departments, employee, manager and technological factors. Each of these categories of determinants encompass at their turn two or more constructs. Competition \& government factors include competition challenges and government implication and support regarding the assistance given to SMEs' ICT issues; ICT providers \& firm departments include cooperation with different interested parties of the company along with the collaboration of the IT unit of company with other departments of the firm, employee factors gather the employees' ICT and cloud know-how together with the employees' access to information within the company, while manager determinants are the decision makers' innovation capacity and their cloud-computing expertise. Before describing the fifth and last category of factors technological it is important to present the hypotheses that follow from the first four classes of variables: competition \& government, ICT providers \& firm departments, employee and manager determinants.

H1: SMEs that function within a more competing business scene are more plausible to adopt cloud computing.

$\mathrm{H}$ 2: Higher volume of tangible government support positively affects the plausibility of cloud computing adoption by SMEs.

H3: SMEs that have stronger, more developed relationships with different ICT providers are more likely to adopt cloud computing.

H4: SMEs in which the IT unit has a closer collaboration with other business units or departments are more likely to adopt cloud computing.

H5: Employee's ICT and cloud know-how is positively related to the adoption of cloud computing.

H6: Employee's access to information with cloud computing is positively to the adoption of cloud computing at company level.

H7: Manager's innovation capacity is positively related to cloud computing adoption.

H8: Manager's cloud-computing expertise and openness is positively related to cloud computing adoption.

The last category of determinants - technological - cover the cloud computing's perceived business benefit, cost reduction, security and privacy, complexity of the respective technology and compatibility with organizational norms and technologies within small firms from the Romanian market. In addition to these factors, trialability is also encompassed, by reason of the significance of this factor when cloud computing is concerned; this is proved by the fact that the preponderance of the noted cloud providing companies like Microsoft provide trial versions of their cloud support. Therefore, in relation to technological determinants, these additional six hypotheses follow:

H9: The business benefit perceived for the company by the manager influences positively the adoption of cloud computing technologies. 
H10: The manager's judgement on cost reduction achieved by adopting cloud computing (by paying only for what is needed and thereby avoiding upfront costs for various resources) has a positive effect on the SMEs' adoption of cloud computing.

H11: The more managers discern cloud computing as being secure, the more they implement cloud computing services within their company (SME).

H12: The complexity of the cloud computing services is positively related to the usage and adoption of cloud by SMEs.

H13: The degree of the compatibility of cloud computing with the firm's organizational culture and technologies has a positive impact on cloud computing adoption.

H14: Higher degree of trialability (possibility and openness to experiment cloud computing trial versions) has a positive impact on cloud computing adoption.

\subsection{Collection of data}

For the completion of the research a quantitative approach was preferred and utilized. Blaikie (2009) explains that a quantitative research method quantifies and measures different characteristics of an event or process. The research instrument used within this research was the questionnaire and managers were asked to fill it in. The quantification tool used for the decision makers' answers was the 5 point Likert-scale. The data collection process was founded on this particular questionnaire, which was analyzed and changed by a group of specialists. The definitive version of the questionnaire was set online. Both cloud computing adopter and non-adopter companies were invited to take part in this survey. Their viewpoint on various aspects of cloud computing was explored regarding technical characteristics along with organizational, people and environmental features of their organization.

a. Questionnaire elaboration

The questionnaire' goal was to achieve the respondents' judgements on cloud computing, and other elements that could persuade them to adopt cloud computing. The first draft of questionnaire contained 55 components, shaped up on a 5 point Likert type scale. A panel of specialists was asked to review the questionnaire and after their feedback, it was launched online. The software that was applied to conceive and build up the online questionnaire was Qualtrics, one of the most frequently used online questionnaire software in both academic and business fields. Because persuading business managers to take part in the research was challenging, a market research company was involved in the study to select the participant firms and to collect data for this study. The final version of the questionnaire consisted in 25 questions with one or more items.

b. Choosing participant firms

400 SMEs from Bucharest and Cluj county received the link to the survey, with 202 not being eligible to continue taking the survey, because they were not meeting the criteria of familiarity with cloud computing and direct involvement in the decision making process within the company. These regions were selected as they slowly become home to innovative digital firms and most of the companies in these regions are SMEs. The "eliminatory" question asked respondents to point out how acquainted they are with cloud computing. Those who selected "poor knowledge" about cloud computing were eliminated from the following 
phases of the study. The process of filtering the eligibility left out 198 completed surveys. It is also necessary to mention that all the SMEs targeted by this study have a maximum of 50 (and not 250) employees because we wanted to focus on the needs and the ways to help companies which have limited resources of all types.

\subsection{Data analysis method}

A quantitative analysis of the gathered data was performed with the support of a specific statistical software program (SPSS version 20). The validity of the model was examined by completing factor analysis and afterwards a logistic regression analysis was deployed to test the research hypotheses. This method gives the possibility to foretell the factors which are significant in predicting the process of adoption of cloud computing.

The construct validity method enables the correlation analysis between items and the creation of a new set of variables which are highly correlated between them, these new variables being called factors. Convergent validity is an integral part of construct validity, which shows if all elements that measure one factor converge. A procedure that examines the convergent validity of the construct is factor loading. Factor loading determines the correlation between each item and the respective construct. Hair, Black, Babin, and Anderson (2010) states that a factor loading higher than 0.5 is sufficient; and the factor loading higher 0.7 is very good. The second stage of construct validity that requires verification is discriminant validity, which reveals the difference between the constructs with the method of cross loading search being the most appropriate. The presence of cross loading implies that the model has a weakness. If cross loading is identified for an item of one construct with items of other constructs it means that the respective item does not really measure only one factor, but more. In order to test discriminant and convergent validity of the model, factor analysis was performed to decrease the amount of factors and to dispose of items that have high cross loadings.

Logistic regression was performed in order to test the hypotheses and predict the process of cloud computing adoption. The coefficients designate the relative effect of the constructs on the dependent variable. In this study the dependent variable is a binary variable (being an adopting firm or non-adopting firm of cloud computing) and logistic regression was performed to distinguish the factors that impact the decision to adopt cloud computing.

\section{Findings}

\subsection{Descriptive analysis}

In this section, descriptive analysis was performed in order to describe each variable of the model in detail. Table 1 comprises characteristics of the respondents (decision makers) and of the companies that they run.

In the following paragraphs the descriptive analysis of the variables (which also stood the test of the factor analysis test presented in the next sub-chapter) is illustrated.

In Table 2 the descriptive analysis of items measuring government implication and support regarding the assistance given to SMEs' ICT issues is summarized. This variable is scaled as the manager's perception on the government's intervention on ICT policy - Gov_ICT 
Table 1. Features of the sample (source: own research)

\begin{tabular}{|c|c|c|c|c|c|}
\hline Features of the sample & Number & $\%$ & Features of the sample & Number & $\%$ \\
\hline \multicolumn{3}{|l|}{ Manager's age } & \multicolumn{3}{|l|}{ Number of employees of the company } \\
\hline $18-27$ & 22 & 11 & 1-10 Employees & 85 & 43 \\
\hline $28-37$ & 51 & 26 & 11-50 Employees & 113 & 57 \\
\hline $38-49$ & 73 & 35 & Total & 198 & 100 \\
\hline $50-63$ & 52 & 28 & \multicolumn{3}{|l|}{ Object of activity of the company } \\
\hline Total & 198 & 100 & Construction & 12 & 6 \\
\hline \multicolumn{3}{|l|}{ Manager's gender } & Consultancy and management & 25 & 13 \\
\hline Female & 42 & 21 & Cultural industry (arts, books, music) & 14 & 7 \\
\hline Male & 156 & 79 & Education & 11 & 5 \\
\hline Total & 198 & 100 & Finance and insurance & 30 & 15 \\
\hline \multicolumn{3}{|c|}{ Manager's education degree } & Health care & 12 & 6 \\
\hline Bachelor's degree & 111 & 57 & Hotel/ Restaurant & 38 & 19 \\
\hline Master's degree & 74 & 37 & Manufacturing & 5 & 3 \\
\hline Doctoral degree & 13 & 6 & Real Estate & 9 & 4 \\
\hline Total & 198 & 100 & Retail (Trade) & 31 & 16 \\
\hline \multicolumn{3}{|c|}{ Manager's industry work experience } & Transportation & 11 & 6 \\
\hline Less than 4 years & 7 & 3 & Total & 198 & 100 \\
\hline $5-10$ Years & 21 & 11 & \multicolumn{3}{|c|}{ Company's existence on the market (in years) } \\
\hline $11-19$ Years & 98 & 49 & $1-5$ Years & 49 & 25 \\
\hline More than 20 Years & 72 & 37 & $6-10$ Years & 62 & 31 \\
\hline \multirow[t]{2}{*}{ Total } & 198 & 100 & More Than 11 Years & 87 & 44 \\
\hline & & & Total & 198 & 100 \\
\hline
\end{tabular}

(setting up infrastructure, investments in $\mathrm{R} \& \mathrm{D}$, facilitating technology transfers, creating legal frameworks, building science parks, etc.), ICT policy for SMEs - Gov_ICTSME (offering tax incentives for ICT investments, subsidies for ICT training within SMEs, providing incentives for e-acquisitions, etc.) and SMEs policy - GovSME (offering SMEs financing and business consultancy services, simplifying bureaucratical procedures, providing tax reductions or exemptions, building incubators, etc.). Figure 3 describes the answers to each of the three items. It should be remarked that for $40 \%$ of more of the respondents the degree of the provided government ICT support is extremely important.

Table 2. Descriptive statistics for the variable government implication

\begin{tabular}{|l|c|c|c|}
\hline & N & Mean & Std. Deviation \\
\hline Gov_ICT & 198 & 4.57 & 0.885 \\
\hline Gov_ICTSME & 198 & 4.16 & 0.891 \\
\hline Gov_SME & 198 & 4.22 & 0.954 \\
\hline
\end{tabular}




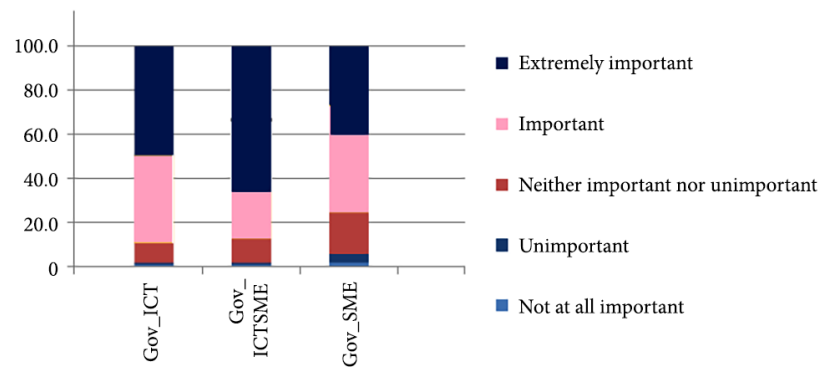

Figure 3. Respondents' viewpoints regarding the variable government implication

Firm cooperation with the ICT providers is evaluated as the manager's understanding about the collaboration with cloud providers regarding the technical assistance (Coop_Assist), the customer service (Coop_CustServ) and the coaching offered by cloud providers(Coop_ Coach). Table 3 gives a synthesis of the descriptive statistics of the items (mentioned above) valuing the firm cooperation with ICT providers variable. As it can be seen in Figure 4 more than $50 \%$ of participant firms perceive the collaboration with cloud providers on the three different levels as being extremely important.

Table 3. Descriptive statistics for the variable firm cooperation

\begin{tabular}{|l|c|c|c|}
\hline & N & Mean & Std. Deviation \\
\hline Coop_Assist & 198 & 4.47 & 0.846 \\
\hline Coop_CustServ & 198 & 4.21 & 0.803 \\
\hline Coop_Coach & 198 & 4.08 & 0.807 \\
\hline
\end{tabular}

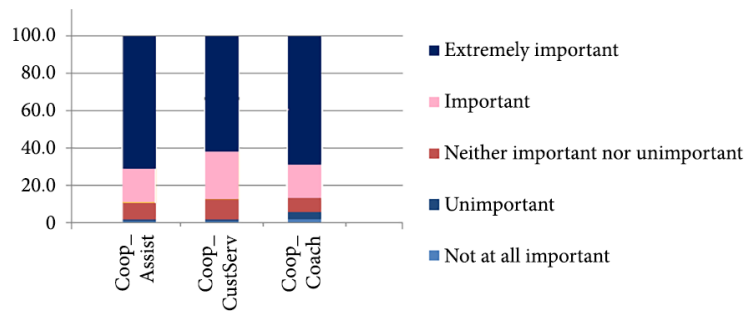

Figure 4. Respondents' viewpoints regarding the variable firm cooperation

The employees' ICT and cloud know-how is assessed taking into consideration the manager's evaluation of the knowledge of their employees about general IT (Empl_IT), theoretical knowledge about cloud computing in particular (Empl_CloudTheor) and their potential previous experience with cloud computing usage (Empl_CloudPrac). In Table 4 the means and standard deviation for the three items above is depicted, while in Figure 5 presents how managers ranked their employees when it came to these three skills. It can be noted that only $50 \%$ of the managers believe that their workers hold knowledge about IT with only $30 \%$ of them thinking that their workers possess know-how or prior experience with cloud computing in particular. 
Table 4. Descriptive statistics for the variable employees' know-how

\begin{tabular}{|l|c|c|c|}
\hline & $\mathrm{N}$ & Mean & Std. Deviation \\
\hline Empl_IT & 198 & 3.95 & 0.741 \\
\hline Empl_CloudTheor & 198 & 3.24 & 0.852 \\
\hline Empl_CloudPrac & 198 & 3.02 & 0.753 \\
\hline
\end{tabular}

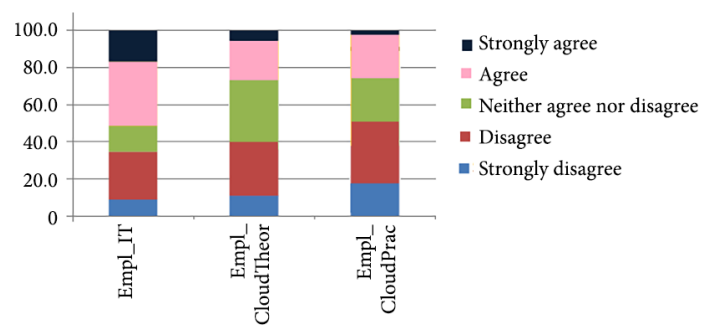

Figure 5. Respondents' viewpoints regarding the variable employees' know-how

The employees' access to information was measured by the managers' point of view regarding: their reliance on current information (Empl_Curr), their reliance on the speed of accessing necessary information (Empl_Speed) and their dependency on accessing solid, suitable and factual information (Empl_ssf). Table 5 reviews the mean and standard deviation of these three items and Figure 6 pictures shows that more than $75 \%$ of participant firms asses the employees' access to information as being moderate or lower.

Table 5. Descriptive statistics for the variable employees' access to information

\begin{tabular}{|l|c|c|c|}
\hline & $\mathrm{N}$ & Mean & Std. Deviation \\
\hline Empl_Curr & 198 & 4.16 & 0.888 \\
\hline Empl_Speed & 198 & 4.84 & 0.902 \\
\hline Empl_ssf & 198 & 4.63 & 0.836 \\
\hline
\end{tabular}

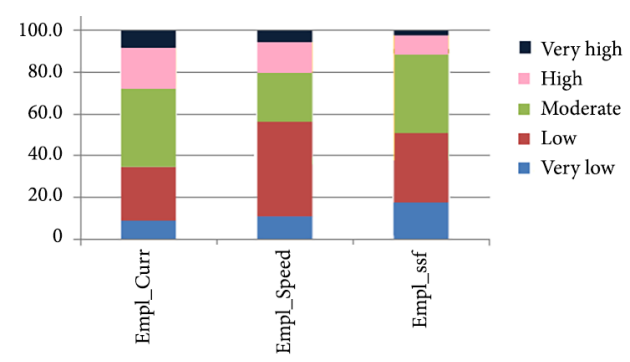

Figure 6. Respondents' viewpoints regarding the variable employees' access to information

The descriptive statistics of the managers' cloud computing expertise of this research's sample is depicted in Table 6. The items include the manager's competences with different 
features of cloud computing: the manager's knowledge on: overall cloud computing (Man CloudOvKnow), the advantages of cloud computing usage (Man_CloudAdv), the different models or deployment models of cloud (Man_CloudMod), the expenses on cloud (Man_ CloudExp). In Figure 7 it can be noticed that the category in which most managers classified their expertise on cloud computing was good.

Table 6. Descriptive statistics for the variable managers' cloud expertise

\begin{tabular}{|l|c|c|c|}
\hline & N & Mean & Std. Deviation \\
\hline Man_CloudOvKnow & 198 & 3.97 & 0.914 \\
\hline Man_CloudAdv & 198 & 4.41 & 0.928 \\
\hline Man_CloudMod & 198 & 4.22 & 0.909 \\
\hline Man_CloudExp & 198 & 4.10 & 0.877 \\
\hline
\end{tabular}

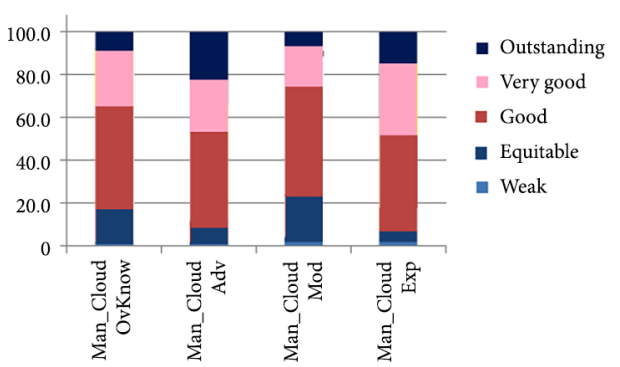

Figure 7. Respondents' viewpoints regarding the variable managers' cloud expertise

In this research the perceived business benefit is seen as: the faster fulfillment of activities (Benef_Fast), the improvement of the work performance (Benef_Perf), the increase of the firm's productivity (Benef_Prod), the enrichment of the organization's data storage space (Benef_Dstor), the improvement of the operational performance (Benef_Oper) and the enhancement of the business as a whole (Benef_GenBus), with descriptive statistics of each item being mentioned in Table 7 . The Figure 8 shows that almost $90 \%$ of managers agree or strongly feel that cloud computing would enhance their business as a whole.

Table 7. Descriptive statistics for thevariable perceived business benefit

\begin{tabular}{|l|c|c|c|}
\hline & N & Mean & Std. Deviation \\
\hline Benef_Fast & 198 & 4.84 & 0.940 \\
\hline Benef_Perf & 198 & 4.29 & 0.902 \\
\hline Benef_Prod & 198 & 4.32 & 0.855 \\
\hline Benef_Dstor & 198 & 4.78 & 0.843 \\
\hline Benef_Oper & 198 & 4.13 & 0.896 \\
\hline Benef_GenBus & 198 & 4.06 & 0.837 \\
\hline
\end{tabular}




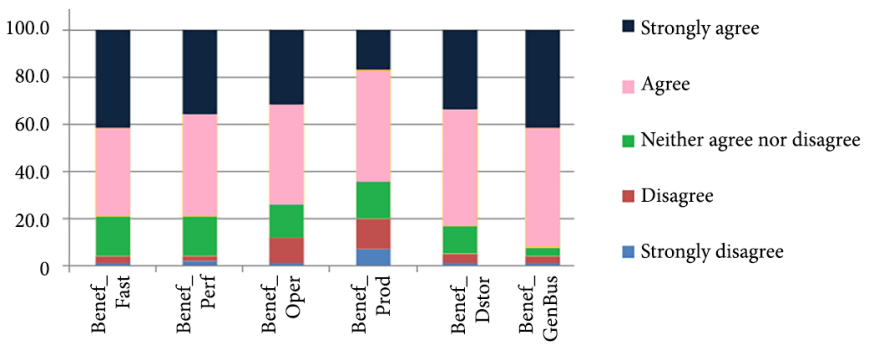

Figure 8. Respondents' viewpoints regarding the variable perceived business benefit

The managers' ideas on the costs with cloud computing are estimated from various outlooks descriptively analyzed in Table 8. Managers were asked if they believe that cloud computing decreases the company's operating costs (Cost_oper), the license cost (Cost_lic), the upgrade \& maintenance cost (Cost_upmnt), the IT staff cost (Cost_ITstaff), the overall business working time (Cost_time) and the general costs (Cost_gen). As it can be recognized in Figure 9 , more than $50 \%$ of the responding firms agree or strongly agree that cloud computing would decrease all types of costs mentioned above.

Table 8. Descriptive statistics for the variable managers' ideas on the costs

\begin{tabular}{|l|c|c|c|}
\hline & N & Mean & Std. Deviation \\
\hline Cost_oper & 198 & 3.65 & 0.818 \\
\hline Cost_lic & 198 & 3.99 & 0.959 \\
\hline Cost_upmnt & 198 & 4.28 & 0.917 \\
\hline Cost_ITstaff & 198 & 4.44 & 0.876 \\
\hline Cost_time & 198 & 3.76 & 0.894 \\
\hline Cost_gen & 198 & 4.16 & 0.872 \\
\hline
\end{tabular}

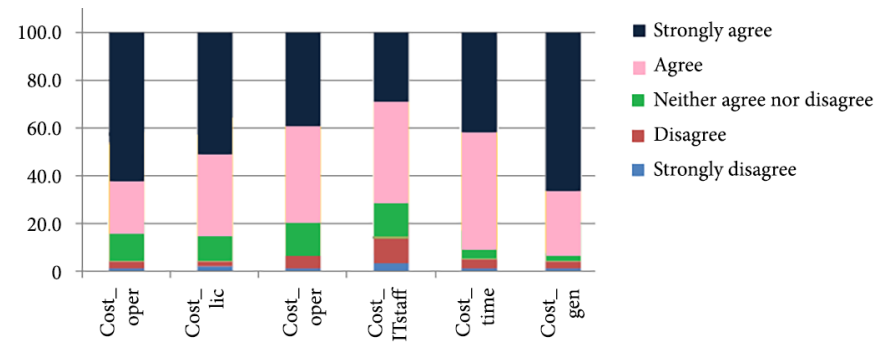

Figure 9. Respondents' viewpoints regarding the variable managers' ideas on the costs

Table 9 integrates the descriptive analysis of items which are associated with security and privacy: the overall protection offered by cloud computing (SecPriv_Ove), the confidence in the servers (SecPriv_Serv), the confidence in the channels that are applied to send the information (SecPriv_Chan) and the privacy of the firm's data (SecPriv_Dat). It can be observed in Figure 10 that more than $75 \%$ of the responding firms agree or strongly agree that cloud 
computing overall and in particular the servers, the channels which transmit the data and the privacy ensured by cloud computing to the company are all trustworthy and safe.

Table 9. Descriptive statistics for the variable security and privacy

\begin{tabular}{|l|c|c|c|}
\hline & N & Mean & Std. Deviation \\
\hline SecPriv_Ove & 198 & 4.19 & 0.857 \\
\hline SecPriv_Serv & 198 & 4.08 & 0.865 \\
\hline SecPriv_Chan & 198 & 4.37 & 0.932 \\
\hline SecPriv_Dat & 198 & 4.26 & 0.814 \\
\hline
\end{tabular}

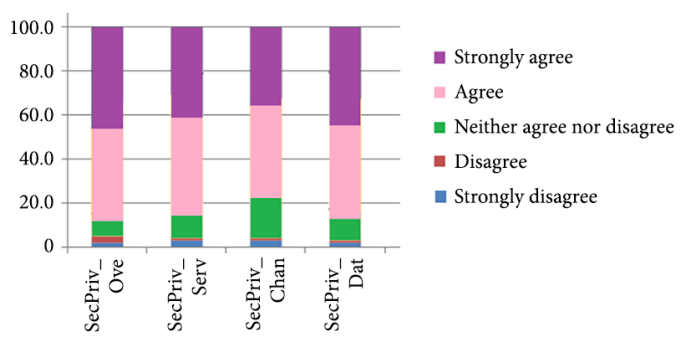

Figure 10. Respondents' viewpoints regarding the variable security and privacy

Table 10 sums up the descriptive analysis of the recognized significance of trialability of cloud computing for the managers. They were asked to specify if the company had chances to test different models of cloud computing (Trial_test), if the trial versions of cloud computing were user-friendly (Trial_friend), and if the possibility existed to get trial versions with potential packages of the cloud computing service at a more advantageous price (Trial_price). It can be observed in Figure 11 the discerned degree of trialability is moderate among managers of the sample, with maximum 55\% of the respondents agreeing or strongly agreeing that cloud computing is triable from all three points of view mentioned above.

Table 10. Descriptive statistics for the variable triability

\begin{tabular}{|l|c|c|c|}
\hline & N & Mean & Std. Deviation \\
\hline Trial_test & 198 & 3.19 & 0.763 \\
\hline Trial_friend & 198 & 3.35 & 0.751 \\
\hline Trial_price & 198 & 3.42 & 0.747 \\
\hline
\end{tabular}

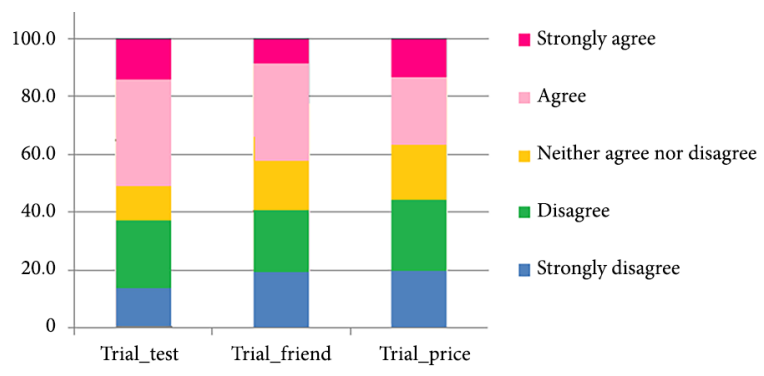

Figure 11. Respondents' viewpoints regarding the variable triability 


\subsection{Factor analysis}

In this section, explanatory factor analysis was performed to reduce the number of unreliable variables (factors) in the research, applying the method of principal component extraction aiming at obtaining Eigenvalues bigger than 1 (significant because the factors are considered reliable). The Varimax rotation method was applied, and taking into consideration the sample size, factors that recorded factor loading of more than 0.50 were considered. 12 different factors were identified previously for the model with more than 2 items each. The items which recorded a factor loading smaller than 0.50 or on the contrary, had high cross loading with more than one other factor (variable/ construct) were automatically deleted from the model. All items being part of the compatibility and complexity factors were eliminated, for having insignificant factor loadings (smaller than 0.50) or for having high cross loadings with other variables (such as security and privacy or employee's know-how and manager's cloud expertise, respectively). All items from the competition challenges and from the collaboration of the firm's IT unit with other departments were deleted as well because they had very small factor loadings. From the rest of ten variables the following items were deleted from the model because they had factor loading lower than the significance level (0.50): Gov_ ICT, Coop_CustServ, Empl_Speed, Man_CloudMod, Benef_Fast, Benef_Prod, Cost_uptmnt, Cost_time, SecPriv_Chan and Trial_friend.

Table 11 below shows all ten factors with eigenvalue above 1 (together with their remaining items): the government support, cooperation with cloud providers, employee's know-how, employee's information access, manager's innovation capacity, manager's cloud expertise, perceived business benefit, cost reduction, security and privacy and trialability. Collectively these ten factors value $82 \%$ of total variance of all the factors in the study which is considered a suitable level of variance. Variables "manager cloud computing expertise", "employee's knowhow" and "perceived business benefit" value for $15.5 \%, 13.2 \%$ and $11.9 \%$ in interpreting the total variance, therefore they hold an important function.

\subsection{Logistic regression}

The process of logistic regression was used in order to test the hypotheses. The dependent variable is the adoption of cloud computing within the company (marked with Yes or No). The independent variables are represented by the composite values determined by the factor analysis. Normality tests were performed for these new variables and the results showed that they are normally distributed. When completing the logistic regression, an essential property of the data that needs to be studied is the multicollinearity. The excellent context takes shape when there is a high correlation between the dependent variables and the independent variable, and a very low correlation between the independent variables.

The most used techniques of investigating multicollinearity of the independent variables are tolerance and variance influence factor (VIF) with a big value of tolerance and a small degree of VIF indicating the desirable low level of multicollinearity. As stated by Yoo et al. multicollinearity can notably impact in the predictability of the model, because if this property is present, it means that the coefficient values are not correctly predicted and the 
independent variables become insignificant (Yoo et al., 2014). The recommendations are a tolerance higher than 0.1 and VIF lower than 10.

Table 11. Factor analysis results

\begin{tabular}{|c|c|c|c|c|c|c|c|c|c|c|}
\hline & & & & & Compo & ient & & & & \\
\hline & 1 & 2 & 3 & 4 & 5 & 6 & 7 & 8 & 9 & 10 \\
\hline $\begin{array}{l}\text { Man_- } \\
\text { CloudOvKnow }\end{array}$ & 987 & & & & & & & & & \\
\hline Man_CloudAdv & 932 & & & & & & & & & \\
\hline Man_Cloud_Exp & 911 & & & & & & & & & \\
\hline Empl_IT & & 894 & & & & & & & & \\
\hline $\begin{array}{l}\text { Empl_} \\
\text { CloudTheor }\end{array}$ & & 875 & & & & & & & & \\
\hline Empl_CloudPrac & & 802 & & & & & & & & \\
\hline Benef_Perf & & & 877 & & & & & & & \\
\hline Benef_Dstor & & & 842 & & & & & & & \\
\hline Benef_Oper & & & 830 & & & & & & & \\
\hline Benef_GenBus & & & 808 & & & & & & & \\
\hline Cost_oper & & & & 851 & & & & & & \\
\hline Cost_lic & & & & 843 & & & & & & \\
\hline Cost_ITstaff & & & & 821 & & & & & & \\
\hline Cost_gen & & & & 807 & & & & & & \\
\hline SecPriv_Ove & & & & & 838 & & & & & \\
\hline SecPriv_Serv & & & & & 819 & & & & & \\
\hline SecPriv_Dat & & & & & 807 & & & & & \\
\hline Coop_Assist & & & & & & 846 & & & & \\
\hline Coop_Coach & & & & & & 731 & & & & \\
\hline Gov_ICTSME & & & & & & & 807 & & & \\
\hline Gov_SME & & & & & & & 798 & & & \\
\hline Empl_Curr & & & & & & & & 787 & & \\
\hline Empl_ssf & & & & & & & & 772 & & \\
\hline Innov_Open & & & & & & & & & 754 & \\
\hline Innov_Acc & & & & & & & & & 733 & \\
\hline Trial_test & & & & & & & & & & 727 \\
\hline Trial_price & & & & & & & & & & 712 \\
\hline Initial Eigenvalue & 3.784 & 3.062 & 2.947 & 2.842 & 2.218 & 1.813 & 1.471 & 1.326 & 1.287 & 1.118 \\
\hline Variance & 15.502 & 13.227 & 11.976 & 9.842 & 8.135 & 7.758 & 6.941 & 4.542 & 2.319 & 1.903 \\
\hline
\end{tabular}

Extraction Method: Principal Component Analysis; Rotation Method: Varimax with Kaiser Normalisation. 
The approach to decrease the negative influence of collinearity is to eliminate the items which hold a high multicollinearity with other factors. In this research the manager's innovation capacity and the manager's cloud expertise recorded a high level collinearity and therefore one of the factors needs to be removed from the model. It was decided due to the SMEs context to keep the manager's cloud expertise as a relevant hypothesis. All results for tolerance and VIF of the independent variables are shown in Table 12 below. Previous to carrying out the logistic regression it is important to inquire to the means for all independent variables in order to see how the data is spread among the two groups of firms: adopting of cloud and non-adopting. In order to test the hypotheses and to assess how the decision of implementing cloud computing varies by each independent variable between the two groups and therefore to test the significance between the groups the One-Way Anova method is conducted.

Table 12. Collinearity results

\begin{tabular}{|l|c|c|}
\hline \multirow{2}{*}{\multicolumn{1}{|c|}{ Independent variable }} & \multicolumn{2}{c|}{ Collinearity Results } \\
\cline { 2 - 3 } & Tolerance & VIF \\
\hline Government support & 0.375 & 3.783 \\
\hline Cooperation with cloud providers & 0.436 & 3.126 \\
\hline Employee's know-how & 0.486 & 4.598 \\
\hline Employee's information access & 0.531 & 7.598 \\
\hline Manager's cloud expertise & 0.852 & 2.854 \\
\hline Perceived business benefit & 0.569 & 2.757 \\
\hline Cost reduction & 0.369 & 3.126 \\
\hline Security and privacy & 0.753 & 2.784 \\
\hline Trialability & 0.697 & 6.487 \\
\hline
\end{tabular}

In Table 13 it can be seen that for the statistic of interest in this case, which is the significance (Sig.) the p-value is smaller than 0.05 for: "manager's cloud expertise", "employee's know-how", "perceived business benefit" and "cost reduction". This can be interpreted that among these variables there are significant differences between the groups. "Cooperation with cloud providers" also holds a $90 \%$ level of significance. Considering that these five variables hold the biggest differences between groups, they have a big potential to shape the logistic regression model.

Logistic regression computes the log likelihood value of all independent variables using the Enter method, with the dependent variable holding the Yes or No values. In order to understand how much variation in the dependent variable can be explained by the model (the equivalent of $\mathrm{R}^{2}$ in multiple regression), the Table 14 below can be consulted. It summarizes the Goodness of fit characteristics of the model: the Cox \& Snell R Square and Nagelkerke R Square results, which are both forms of determining the explained variation. These values are also called pseudo $\mathrm{R}^{2}$ values (and compute lower results than the ones from multiple regression) (Engle \& McFadden, 1994). In our model, the explained variation in the dependent variable spans from $52.9 \%$ to $65.3 \%$, whether the Cox \& Snell $\mathrm{R}^{2}$ or Nagelkerke $\mathrm{R}^{2}$ 
Table 13. Descriptive statistics of groups - Ony Way ANOVA test

\begin{tabular}{|l|c|c|c|}
\hline \multirow{2}{*}{\multicolumn{1}{c|}{ Independent variable }} & $\begin{array}{c}\text { Mean difference between } \\
\text { groups }\end{array}$ & \multicolumn{2}{c|}{$\begin{array}{c}\text { Group Means } \\
\text { Test of equality }\end{array}$} \\
\cline { 2 - 4 } & $\begin{array}{c}\text { (Mean Adopting-firms) - } \\
\text { (Mean Non-adopting firms) }\end{array}$ & $\mathrm{F}$ & Sig. \\
\hline Government support & 0.1596 & 1.998 & 0.248 \\
\hline Cooperation with cloud providers & 0.2797 & 5.128 & 0.081 \\
\hline Employee's know-how & 0.5912 & 12.785 & 0.002 \\
\hline Employee's information access & 0.0269 & 0.984 & 0.573 \\
\hline Manager's cloud expertise & 0.7614 & 37.433 & 0.000 \\
\hline Perceived business benefit & 0.5148 & 9.784 & 0.001 \\
\hline Cost reduction & 0.4482 & 7.421 & 0.008 \\
\hline Security and privacy & 0.1258 & 1.975 & 0.214 \\
\hline Trialability & 0.1983 & 2.147 & 0.358 \\
\hline
\end{tabular}

methods are referred. If the interpretative criteria are applied for these values, the relationship would characterize as strong because theoretically $\mathrm{R}$ ranges from 0 to 1 with bigger values indicating better model fit. The second measure of model fit is the Hosmer and Lemeshow goodness-of-fit statistic (Table 15), which measures the correspondence between the actual and predicted values of the dependent variable (Engle \& McFadden, 1994). In this study, better model fit by a smaller difference in the observed and predicted values with a good model fit being indicated by a nonsignificant chi-square value. In this case the Hosmer-Lemeshow results provide evidence that the test is not statistically significant and therefore the model is predictive since $\mathrm{p}>0.05$.

Table 14. The Goodness of Fit for the researched model

\begin{tabular}{|c|c|c|c|}
\hline Step & -2 Log likelihood & Cox\& Snell $\mathrm{R}^{2}$ & ${\text { Nagelkerke } \mathrm{R}^{2}}^{2}$ \\
\hline 1 & 10.754 & 0.529 & 0.653 \\
\hline
\end{tabular}

Table 15. The Hosmer and Lemeshow test

\begin{tabular}{|c|c|c|}
\hline Step & Chi-square & Sig. \\
\hline 1 & 10.861 & 0.257 \\
\hline
\end{tabular}

In order to evaluate the model's goodness of fit the method of classification accuracy was also used and the results of applying the method on the model are synthesized in table 16. It is noted that for $62 \%$ of the sample a non-adopting firm is accurately predicted as being non-adopting. The number is bigger for adopting firms with $93 \%$ of the cases being correctly predicted. The model's classification accuracy is 80.1616 , which implies that in $80.16 \%$ of the cases the model accurately predicted the decision of cloud computing implementation. This level of prediction accuracy is significant. If the decision within the sample was settled 
by random choice ( 82 non-adopting companies and 116 adopting firms), it would proceed from $(82 / 198)^{2}+(116 / 198)^{2}$ which amounts to $51.474 \%$. It is deduced that the outcomes of the logistic regression have a higher predictive degree than the random choice procedure.

Table 16. Classification of accuracy of the researched model

\begin{tabular}{|c|c|c|c|}
\hline \multirow{2}{*}{ Observed } & \multicolumn{3}{|c|}{ Predicted } \\
\cline { 2 - 4 } & \multicolumn{2}{|c|}{ Adoption } & Percentage Correct \\
\cline { 2 - 4 } & No & Yes & \\
\hline Adoption No & 51 & 108 & 62.195 \\
\hline Yes & 8 & & 93.103 \\
\hline Overall Percentage & & & 80.1616 \\
\hline
\end{tabular}

Generally, considering the results of all three tests, it can be deduced that the goodness of fit of the model is good. The next step would be to examine the correlation between the dependent variable and the independent variables and to uncover if a significant rapport between the variables exists. Table 17 outlines the findings of the regression which show that from the nine independent variables three of them have a significant relationship with the decision to implement cloud computing (the independent variable): manager's cloud expertise, cooperation with ICT and cloud providers and cost reduction with their afferent hypotheses. From the original and exponential coefficients, the orientation and width of the correlation can be acknowledged. The Wald test (Wald column) is utilized to decide on the statistical significance for each of the independent variables. The statistical significance of the test is found in the "Sig." column with significant variables recording values smaller than 0.05 for this column. From the table it can be seen that the "manager's cloud expertise" ( $p=0.021)$, the "cooperation with ICT and cloud providers" $(\mathrm{p}=0.000)$ and the "cost reduction" ( $\mathrm{p}=$ 0.011 ) add significantly to the model/ prediction, but all the other six variables did not. All these three variables are positively correlated with the cloud adoption decision (shown by the sign of the coefficient B). Specifically, the probability of implementing cloud computing is higher for managers who hold a greater expertise on cloud computing, who have a better knowledge about the costs operate by cloud computing and who cooperate better with cloud providers. The findings of logistic regression are grounded on odds of happening. For example, for an additional unit increase in cloud expertise the odds of implementing cloud computing increases by a factor of 1.950 (B column). The notion of odds ratio represents the ratio of the probability of that phenomenon occurring over the probability of that phenomenon not occurring (P (accomplishment)/P(flop)). According to the results, keeping the other variables on a fixed value, for each one-unit increase in the cloud expertise the odds of implementing cloud computing within the company increases by $602 \%$. In the logistic regression processing the value of $\operatorname{Exp}(B)$ minus 1 produces the percentage modification in odds (Hair et al., 2010).

The findings of the regression analysis proved that the three factors which have a statistically significant correlation with the decision of implement cloud computing are: the "manager's cloud expertise", the "cooperation with ICT and cloud providers" and the "cost reduction" proving that only $\mathrm{H} 3, \mathrm{H} 8$ and $\mathrm{H} 10$ are confirmed. The rest of the eleven factors 
do not hold a statistically significant impact on the decision to implement cloud computing and therefore the according eleven hypotheses are not confirmed.

Table 17. Results of the logistic regression

\begin{tabular}{|l|c|c|c|c|c|c|}
\hline & B & S.E. & Wald & df & Sig. & Exp(B) \\
\hline Government support & 0.263 & 0.332 & 0.629 & 1 & 0.428 & 1.301 \\
\hline Cooperation with ICT \& cloud providers & 1.592 & 0.413 & 14.854 & 1 & $0.000^{\star}$ & 4.915 \\
\hline Employee's know-how & 0.601 & 0.618 & 0.944 & 1 & 0.331 & 1.824 \\
\hline Employee's information access & 0.120 & 0.568 & 0.045 & 1 & 0.832 & 1.128 \\
\hline Manager's cloud expertise & 1.950 & 0.842 & 5.356 & 1 & $0.021^{\star}$ & 7.026 \\
\hline Perceived business benefit & 2.342 & 1.680 & 1.943 & 1 & 0.163 & 10.399 \\
\hline Cost reduction & 0.474 & 0.185 & 6.536 & 1 & $0.011^{\star}$ & 1.606 \\
\hline Security and privacy & 0.011 & 0.034 & 1.486 & 1 & 0.749 & 1.011 \\
\hline Trialability & 0.058 & 0.532 & 0.012 & 1 & 0.913 & 1.060 \\
\hline Constant & 0.265 & 1.242 & 0.045 & 1 & 0.831 & - \\
\hline
\end{tabular}

${ }^{\star}$ Correlation is significant at the 0.05 level.

The results show that for managers whose expertise about different characteristics of cloud computing is high, it is more plausible that they implement the respective technology within their company. This is logical because not holding enough information and competences in any technology raises the hesitations and incertitude about the technology. In the same time having a strong relationship with ICT proving companies (which can also offer cloud computing services) increases the decision of implementation. Ultimately the results demonstrate that SMEs whose managers that have a current approach about the cloud costs and the potential decrease of company's overall costs coming from implementing the technology, naturally increase the chances of adopting cloud computing. This is also coherent because firms, especially those of smaller dimensions, do not have the possibility to invest much money on new technologies so they try to document themselves on whatever chance to decrease the general costs in order to make the correct decision.

\section{Conclusions}

This study makes a contribution to the academic environment but to businesses as well. Companies which offer cloud computing services could take advantage of the outcomes of this study to expand the degree of cloud service introduction among SMEs. Taking into account the findings of this investigation, the know-how and experience on cloud computing represent the main components influencing the spreading of cloud computing among Romanian small and medium businesses. Cloud providing companies can make use of the many social networking companies like Facebook, LinkedIn, Instagram and Twitter with the goal to make SMEs more aware about the benefits of cloud computing. In this study's sample SMEs obtain the biggest amount of information from cloud providing businesses. However, the SMEs choice to implement or cease using cloud computing should be grounded on elaborate 
and meticulous analysis techniques (cost-benefit, cost-effectiveness, risk-benefit etc.), and not just on the media promotion. The article puts forward a very current topic even from political and social points of views as, in 2019, the Romanian Ministry of Communications and Informational Society is planning to develop the governmental cloud computing and the social media communication through projects affiliated with the Ministry of the European Funds. The main benefit in implementing the government cloud projects is to reduce spending among public institutions and reinforce data security and confidentiality within the digital space (Ministry of Communications and Informational Society, 2018).

This study presents a few limitations as well. One of the matters of concerns would be the fact that the data is provided by SMEs from different industries and studies anchored in particular industries are more suggested. Another issue would be the size of the sample (198 companies) which is not small, but the process of logistic regression gives significant results for more independent variables when the sample is of a few hundreds. However, in our case significant results were obtained for three from eleven variables which is an acceptable state of findings. The process of collecting data from more than 200 companies was restricted because of budget constraints. Furthermore, another possible limitation to remark (inherent to the survey methodology) could be the possibility of respondent bias since those that are more familiar and favorable to Cloud Computing could have a positive bias towards its adoption. With everything considered, the findings of this research cannot be generalized and further studies are needed to achieve a complex understanding of this phenomenon.

\section{Acknowledgements}

We are thankful to the anonymous reviewers for their valuable and practical advice, which helped us to improve our research.

\section{Funding}

The research published in this article has been supported by the Romanian government through CERTRAN project - The Upgrade of the Research Capacity in Economics through Development of a Transdisciplinary Research Infrastructure.

\section{Author contributions}

Violeta Mihaela Dincă conceptualized the research and advanced the statistical analysis contributing to the data collection. Alina Mihaela Dima was responsible for the theoretical background and for the data analysis. Zoltan Rozsa shaped the study framework and gave input for the recommendations and conclusions sections.

\section{Disclosure statement}

Authors do not have any competing financial, professional, or personal interests from other parties. 


\section{References}

Alshamaila, Y., Papagiannidis, S., \& Li, F. (2013). Cloud computing adoption by SMEs in the north east of England: A multi-perspective framework. Journal of Enterprise Information Management, 26(3), 250-275. https://doi.org/10.1108/17410391311325225

Balcerzak, A. P., \& Pietrzak, M. B. (2017). Digital economy in Visegrad countries. Multiple-criteria decision analysis at regional level in the years 2012 and 2015. Journal of Competitiveness, 9(2), 5-18. Retrieved from https://www.cjournal.cz/files/246.pdf

Blaikie, N. (2009). Designing social research (2nd ed.). Cambridge: Polity Press.

Buchaelcevova, A., \& Gala, L. (2012). Green ICT adoption survey focused on ICT life-cycle from the consumer's perspective (SMEs). Journal of Competitiveness, 4(4), 109-122. https://doi.org/10.7441/joc.2012.04.08

Buyya, R., Yeo, C. S., Venugopal, S., Broberg, J., \& Brandic, I. (2009). Cloud computing and emerging IT platforms: vision, hype, and reality for delivering computing as the 5th utility. Future Generation Computer Systems, 25(6), 599-616. https://doi.org/10.1016/j.future.2008.12.001

Cepel, M., Stasiukynas, A, Kotaskova, A., \& Dvorsky, J. (2018). Business environment quality index in the SME segment. Journal of Competitiveness, 10(1), 21-40. https://doi.org/10.7441/joc.2018.02.02

Choi, H., Kim, S. H., \& Lee, J. (2010). Role of network structure and network effects in diffusion of innovations. Industrial Marketing Management, 39(1), 170-177. https://doi.org/10.1016/j.indmarman.2008.08.006

Dobeš, K., Kot, S., Kramoliš, J., \& Sopková, G. (2017). The perception of governmental support in the context of competitiveness of SMEs in the Czech Republic. Journal of Competitiveness, 9(3), 34-50. https://doi.org/10.7441/joc.2017.03.03

Engle, R., \& McFadden, D. L. (1994). Handbook of econometrics, 4. Amsterdam: North Holland.

European Commission. (2016). 2016 SBA fact sheet. Working paper. European Commission. Retrieved from https://ec.europa.eu/jrc/sites/jrcsh/files/eu28_sba_fact_sheet.pdf

Foerster-Pastor, U. S., \& Golowko, N. (2018). The need for digital and soft skills in the Romanian business service industry. Management \& Marketing. Challenges for the Knowledge Society, 13(1), 831-847. https://doi.org/10.2478/mmcks-2018-0008

Fonseca, L. M., \& Domingues, J. P. (2017). How to succeed in the digital age? Monitor the organizational context, identify risks and opportunities, and manage change effectively. Management \& Marketing. Challenges for the Knowledge Society, 12(3), 443-455. https://doi.org/10.1515/mmcks-2017-0027

Greavu-Șerban, V. (2015). Cloud computing: Caracteristici și modele. Bucharest: ASE Publishing House.

Gupta, P., Seetharaman, A., \& Raj, J. R. (2013). The usage and adoption of cloud computing by small and medium businesses. International Journal of Information Management, 33, 861-874. https://doi.org/10.1016/j.ijinfomgt.2013.07.001

Hadad, S. (2017). Strategies for developing knowledge economy in Romania. Management \& Marketing, Challenges for the Knowledge Society, 12(3), 416-430. https://doi.org/10.1515/mmcks-2017-0025

Hair, J. F., Black, W. C., Babin, B. J., \& Anderson, R. E. (2010). Multivariate data analysis (7th ed.). London: Pearson.

Henderson, J., \& Weiler, S. (2010). Entrepreneurs and job growth: probing the boundaries of time and space. Economic Development Quarterly, 24(1), 23-32. https://doi.org/10.1177/0891242409350917

Jain, V. (2011). How the cloud resonates with business today. Siliconindia 14(10), 22-23.

Kallier, S. M. (2017). The focus on marketing communication efforts of SMEs. Management \& Marketing. Challenges for the Knowledge Society, 12(1), 140-154. https://doi.org/10.1515/mmcks-2017-0009 
Mell, P., \& Grance, T. (2011). The NIST definition of cloud computing (Technical report 800-145). National Institute of Standards and Technology.

Microsoft. (2017). Cutting costs in the cloud with Skype for Business. Retrieved from https://www.microsoft.com/itshowcase/Article/Content/944/Cutting-costs-in-the-cloud-with-Skype-for-Businessand-Office-365

Ministry of Communications and Informational Society. (2018). Governmental cloud, a benefice for institutions. Retrieved from https://www.comunicatii.gov.ro/cloud-ul-guvernamental-un-beneficiupentru-institutii/

Nistoreanu, P., Dinca, V. M., \& Schiopu, A. F. (2017). Competition policy in the European film industry focused on consumers' interests - a Romanian perspective. Amfiteatru Economic, 19(45), 397-413.

Plummer, D. C., Bittman, J., Austin, T., Cearley, D. W., \& Smith, D. W. (2008). Cloud computing: Defining and describing an emerging phenomenon (Technical report No. G00156220). Gartner.

Rogers, E. M. (2003). Diffusion of innovations (5th ed.). USA: Free Press.

Sasikala, P. (2011). Cloud computing: present status and future implications. International Journal of Cloud Computing, 1(1), 23-36. https://doi.org/10.1504/IJCC.2011.043244

Smith, D., Cearley, D., \& Plummer, D. (2009). Key issues for cloud computing. Stamford, Connecticut: Gartner.

Stevenson, A. (2015). Oxford Dictionary of English (3 ed.). Oxford: University Press.

Sultan, N. A. (2011). Reaching for the cloud: how SMEs can manage. International Journal of Information Management, 31, 272-278. https://doi.org/10.1504/IJCC.2011.043244

Tornatzky, L. G., \& Fleischer, M. (1990). The processes of technological innovation. Lanham, Maryland: Lexington Books.

Tvrdikova, M. (2013). Increasing the business potential of companies by ensuring continuity of the development of their information systems by current information technologies. Journal of Business Economics and Management, 17(3), 475-489. https://doi.org/10.3846/16111699.2013.839475

Yoo, W., Mayberry, R., Bae, S., Singh, K., He, Q., \& Lillard, Jr. J. W. (2014). A study of effects of multicollinearity in the multivariable analysis. International Journal of Applied Science and Technology, 4(5), 9-19.

Zell, S., \& Swanson, B. (2017). How cloud computing enables modern manufacturing. Retrieved from http://www2.itif.org/2017-cloud-computing-enables-manufacturing.pdf 